\title{
Faceted shell structure in grain boundary diffusion-processed sintered Nd-Fe-B magnets
}

\author{
U.M.R. Seelam, T. Ohkubo, T. Abe, S. Hirosawa and K. Hono \\ Elements Strategy Initiative Center for Magnetic Materials (ESICMM) \\ National Institute for Materials Science \\ 1-2-1 Sengen, Tsukuba 305-0047, Japan
}

\begin{abstract}
Dysprosium enriched shell structure formed by the grain boundary diffusion process (GBDP) of a sintered $\mathrm{Nd}-\mathrm{Fe}-\mathrm{B}$ magnet was characterized by using scanning electron microscopy, electron back-scattered diffraction and transmission electron microscopy. Faceted core-shell interfaces with an abrupt change in Dy concentration suggest the Dy-rich shells are formed by the solidification of the liquid phase during cooling from the GBDP temperature. The Nd-rich phases are almost free from Dy, and their quantity near the surface of a bulk sample is much higher than that in the center, indicating that a higher fraction of a liquid phase exists near the surface during processing at $900{ }^{\circ} \mathrm{C}$. These microstructural features are explained on the basis of the phase equilibrium between $\mathrm{Nd}$ and $\mathrm{Nd}_{2} \mathrm{Fe}_{14} \mathrm{~B}$ at the processing temperature and subsequent cooling. Based on the results, we discuss the coercivity enhancement by the GBDP using Dy vapor.
\end{abstract}

Keywords: Nd-Fe-B, permanent magnet, coercivity, Dy, grain boundary diffusion process 


\section{Introduction}

High performance $\mathrm{Nd}-\mathrm{Fe}-\mathrm{B}$ permanent magnets are currently in great demand for a variety of applications; however, the coercivity is too low for certain major applications such as traction motors of (hybrid) electric vehicles and wind turbines. Partial substitution of Dy for $\mathrm{Nd}$ in the $\mathrm{Nd}_{2} \mathrm{Fe}_{14} \mathrm{~B}$ main phase is known to be effective to enhance the coercivity of Nd-Fe- $\mathrm{B}$ sintered magnets [1]. However, the reduction of the usage of Dy from the high coercivity (Nd,Dy)-Fe-B sintered magnets is now strongly desired because of their high cost and the scarcity of the natural resources [2]. Another demerit of the Dy substitution is the reduction of the remanence due to the antiferromagnetic coupling between Dy and Fe atoms.

In order to reduce the Dy usage and to minimize the loss in remanence, a method known as 'grain boundary diffusion process' (GBDP) was developed [3-6]. This is a method of incorporating heavy rare earth element (HRE) such as Dy or Tb through the grain boundaries of sintered $\mathrm{Nd}-\mathrm{Fe}-\mathrm{B}$ magnets at elevated temperatures keeping the majority of the $\mathrm{Nd}_{2} \mathrm{Fe}_{14} \mathrm{~B}$ grain intact. This process has been industrially implemented to manufacture high coercive and high remanence Nd-Fe-B based sintered magnets [7]. In this process, Dy is considered to diffuse through grain boundaries (GBs) to form $\left.\left(\mathrm{Nd}_{1-\mathrm{x}} \mathrm{Dy}\right)_{\mathrm{x}}\right)_{2} \mathrm{Fe}_{14} \mathrm{~B}$ shells surrounding the $\mathrm{Nd}_{2} \mathrm{Fe}_{14} \mathrm{~B}$ grains $[8,9]$. The higher magneto-crystalline anisotropy of the Dy-rich shell is considered to suppress the nucleation of reverse domains at low magnetic field.

In detailed microstructure characterization of Dy-diffusion processed sintered magnets, Sepehri-Amin et al. reported a unique shell structure that is difficult to explain by the solid diffusion of Dy from grain boundaries to the $\mathrm{Nd}_{2} \mathrm{Fe}_{14} \mathrm{~B}$ grains, i.e., the shells are primarily formed on one side rather than both sides along GBs [8]. For solid state diffusion, the shells should form on both sides of GBs. Although there are several reports on the formation of the 
shell structure both in Dy or Tb GBDP sintered Nd-Fe-B magnets [5, 8-18], all previous investigations overlooked this asymmetric nature of the Dy-rich shell along GBs. A better understanding on the origin of the unique asymmetric feature of the Dy-rich shell should shed light on the mechanism of the microstructure evolution that contribute to the coercivity enhancement. Hence, in this work, we focus on identifying microstructure features of the Dy-rich shells. For characterization of the orientation of the interfaces between the Dy-rich shells and surrounding $\mathrm{Nd}_{2} \mathrm{Fe}_{14} \mathrm{~B}$ grains, we employed electron backscatter diffraction (EBSD) technique, which was first employed to the texture analysis of $\mathrm{Nd}-\mathrm{Fe}-\mathrm{B}$ sintered magnets by Khlopkov, et al. [19] and more recently by Woodcock et al. [20]. In the present work, we have found faced core/shell structure in the GBDP sintered magnets and the faceting planes were identified by EBSD.

\section{Experimental Procedure}

The nominal composition of the sintered magnet used for this study was $\mathrm{Nd}_{23.9} \mathrm{Pr}_{6.6} \mathrm{Dy}_{0.6} \mathrm{Fe}_{65.6} \mathrm{Co}_{2.1} \mathrm{~B}_{0.9} \mathrm{Ga}_{0.1} \mathrm{Cu}_{0.1}$ (mass \%) or $\mathrm{Nd}_{10.9} \mathrm{Pr}_{3.1} \mathrm{Dy}_{0.2} \mathrm{Fe}_{77.5} \mathrm{Co}_{2.4} \mathrm{~B}_{5.7} \mathrm{Ga}_{0.1} \mathrm{Cu}_{0.1}$ (at.\%). The coercivity and the maximum energy product of the sample with the dimensions of $5 \times 5 \times 5.5 \mathrm{~mm}^{3}$ were $1.31 \mathrm{~T}$ and $398 \mathrm{~kJ} / \mathrm{m}^{3}$ respectively, before applying the Dy grain boundary diffusion process. The sample was kept in a saturated Dy vapor atmosphere in a closed vacuum chamber at $\sim 900{ }^{\circ} \mathrm{C}$, an optimized temperature after trial and error, for the grain boundary diffusion process (GBDP). A further low temperature thermal treatment was carried out at about $550{ }^{\circ} \mathrm{C}$ under an Ar atmosphere for $1-3 \mathrm{~h}$. The coercivity was improved from $1.31 \mathrm{~T}$ to $2.04 \mathrm{~T}$ while the remanence dropped marginally from $1.44 \mathrm{~T}$ to $1.42 \mathrm{~T}$. The detailed magnetic properties of this sample were reported elsewhere [8]. 
Microstructures were observed from the surface and the center of the bulk sample. The sample surface was polished using Ar ion mill for microstructural observation and electron back-scattered diffraction (EBSD) analysis. About $50 \mu \mathrm{m}$ from the surface of the magnet was removed during the ion milling, and this region is denoted as 'surface'. The polished surface was observed in a field emission gun scanning electron microscope (Carl Zeiss CrossBeam 1540EsB), in which, the backscattered electron (BSE) micrographs, EBSD data and energy dispersive spectroscopy (EDS) maps were recorded from the same locations on the sample for comparative study. $2 \mathrm{kV}$ electron beam was used for BSE imaging, $20 \mathrm{kV}$ beam was used for EBSD analysis and $15 \mathrm{kV}$ beam was used for EDS mapping. For EBSD data acquisition, the sample was also tilted $70^{\circ}$ from the horizontal position to allow the diffracted beam to be detected by a phosphor screen in the form of Kikuchi bands. The EBSD mapping was carried out with an automatic mode using HKL software. The step size used was $0.1 \mu \mathrm{m}$. At least 4 Kikuchi bands were used for the indexing at each location. The main objective of this work was to obtain orientations of the core/shell interfaces present in the $\mathrm{Nd}_{2} \mathrm{Fe}_{14} \mathrm{~B}$ and $(\mathrm{Nd}, \mathrm{Dy})_{2} \mathrm{Fe}_{14} \mathrm{~B}$ grains. Hence in the EBSD acquisition, only $\mathrm{Nd}_{2} \mathrm{Fe}_{14} \mathrm{~B}$ phase (tP68) was considered for indexing. The Nd-rich phases were ignored because they could produce artefacts in the EBSD data and also hinder automatic indexing $[19,20]$. Scanning transmission electron microscopy (STEM) was performed in a Titan G2 80 transmission electron microscope (TEM) to study the chemical composition. Using the STEM/EDS mapping, elemental distributions and their concentration profiles were acquired. Thermodynamic calculations were performed using Thermo-Calc software to estimate the fraction of phases present at the GBDP temperature.

\section{Results}




\subsection{Faceting}

Fig. 1(a) shows a BSE micrograph of the GBDP Nd-Fe-B sintered magnet from the surface of the sample with its c-axis in the plane of observation (c-in-plane). The light gray region along grain boundaries is shell and the dark contrast region is $\mathrm{Nd}_{2} \mathrm{Fe}_{14} \mathrm{~B}$ main phase grain (core). Usually there is a sudden change in contrast from shell to core. Also, very frequently the interface between the core and the shell is faceted. In addition, the shells are frequently observed only on one side of the grain boundaries. At a few places, core regions are imaged with bright contrast. This feature is usually observed in the magnets processed by the two-alloy method. This originates from the existence of small amount of Dy (0.2 at.\% in this case) in the magnet prior to GBD process.

In order to find the preferred orientations of the shells and the orientation of the core-shell interfaces, EBSD analysis was carried out. Fig. 1(b) shows crystal orientation map from the same region as in Fig. 1a. From the recorded EBSD data, a representative unit cell containing crystal orientations (angles), that is called as 'three-dimensional crystal profile' (3DXP) for each of the $\mathrm{Nd}_{2} \mathrm{Fe}_{14} \mathrm{~B}$ grains was obtained. Typical 3DXP embedded inside the corresponding $\mathrm{Nd}_{2} \mathrm{Fe}_{14} \mathrm{~B}$ grain is shown in Fig. 1(b) and Fig. 1(c). In this case, the unit cell is tetragonal $\mathrm{Nd}_{2} \mathrm{Fe}_{14} \mathrm{~B}$. The arrows in Fig. 1(c) represent the projections of the c-axis directions. The traces of the core-shell interfaces were marked with the lines as shown. These traces were found to be nearly parallel to certain low-index crystallographic directions of their respective 3DXPs. For example in Fig. 1(c), referring to the grain with embedded 3DXP (which is also zoomed and indexed in the top-right corner), the trace of the core-shell interface ' $\mathrm{X}$ ' is parallel to the [100] direction of the 3DXP. Similarly, the trace of the core-shell interface ' $Z$ ' is parallel to the [101] direction. Such indexing is carried out on all the core-shell interfaces. The 
measured angles between the faceted planes matched well with the calculated angles for the tetragonal $\mathrm{Nd}_{2} \mathrm{Fe}_{14} \mathrm{~B}$ crystal structure within an error of $\pm 3^{\circ}$. Based on the trace direction of the core-shell interfaces and the measured angular relationships among the planes, the traces directions were $\langle 100\rangle,\langle 001\rangle$, and $\langle 011\rangle$. The grains of sintered magnets are aligned towards c-axis during magnetic alignment process. This makes $\mathrm{Nd}_{2} \mathrm{Fe}_{14} \mathrm{~B}$ grains amenable to the above type of analysis by minimizing the effects caused by two-dimensional projection of the three-dimensionally distributed core/shell interfaces. About 100 core-shell interfaces were analyzed for this study. Faceting was observed in the c-axis out-of-plane view as shown in Fig. 2(a). Fig. 2(b) shows tracing of Fig. 2(a) for better clarity with indices of the trace directions. The orthogonal arrows in Fig. 2(b) embedded inside $\mathrm{Nd}_{2} \mathrm{Fe}_{14} \mathrm{~B}$ grains indicate a-axis and b-axis components of the corresponding $\mathrm{Nd}_{2} \mathrm{Fe}_{14} \mathrm{~B}$ crystal orientation projected on the observed plane. The dominant trace directions of the facets are parallel to $<100>$ directions. The EBSD maps of both c-axis in-plane and out-of-plane directions showed that there is no misorientation at the core/shell interfaces.

\subsection{Microstructure}

Fig. 3 shows BSE images recorded from the surface (a, c) and center of the sample (b, d) at different magnifications. The brightly imaging phases are Nd-rich phases. The areal fraction of the Nd-rich phases near the surface (8-11\%) was higher than at the center $(5-6 \%)$. Furthermore, the thickness of the Nd-rich grain boundary (GB) phase that is encapsulating the $\mathrm{Nd}_{2} \mathrm{Fe}_{14} \mathrm{~B}$ grains was thicker near the surface compared to at the center. The shells were distributed widely near the surface (Fig. 1 and Fig. 3) having up to about $5 \mu \mathrm{m}$ in thickness with their areal fraction about 6-15\%. In contrast, shells at the center were very thin in thickness and 
weak in contrast, hence difficult to observe them in the BSE images.

Fig. 4 shows a BSE image and EDS elemental maps of Nd, Dy, Fe, and O of a region from the surface of the sample which contains core-shell structure. From the mapping, four different phase features were observed, namely $\mathrm{Nd}_{2} \mathrm{Fe}_{14} \mathrm{~B}$ cores, Dy enriched $(\mathrm{Nd}, \mathrm{Dy})_{2} \mathrm{Fe}_{14} \mathrm{~B}$ shells, metallic Nd-rich phases, and Dy-enriched Nd-oxides. Interestingly the metallic Nd-rich phases were not enriched in Dy. In order to compare the relative Dy content in the above phases, the ratio of $\mathrm{Dy} /(\mathrm{Nd}+\mathrm{Pr}+\mathrm{Dy})$ was evaluated from the EDS analysis. Table 1 shows the estimated quantities of the elements Dy, Fe, $\mathrm{Nd}+\mathrm{Pr}$ and $\mathrm{O}$. In the metallic $\mathrm{Nd}$, the ratio is only 0.0054 ( $\sim .5 \%)$, which is essentially Dy-free $\alpha-\mathrm{Nd}$. On the other hand, the Dy ratios in the $(\mathrm{Nd}, \mathrm{Dy})_{2} \mathrm{Fe}_{14} \mathrm{~B}$ shell and the $(\mathrm{Nd}, \mathrm{Dy}) \mathrm{O}_{\mathrm{x}}$ are comparable $(0.11$ and 0.12$)$, and much more than that in the $\alpha-\mathrm{Nd}$, indicating that Dy is enriched more in the shells and oxide phases than in the $\alpha-\mathrm{Nd}$. The enrichment of Dy in the oxides indicates that Dy is substituted to the $\mathrm{Nd}$ in $\mathrm{NdO}_{\mathrm{x}}$ as reported by Li et al. [21] in the sintered magnets prepared by the two-alloy method. Similarly Dy substitute for the $\mathrm{Nd}$ in the $\mathrm{Nd}_{2} \mathrm{Fe}_{14} \mathrm{~B}$ phase to form the shells. The concentration of $\mathrm{Dy}$ in the shell gradually increases from the core/shell toward the GB. This feature is discussed later. The interface between the Dy-rich shell and the $\mathrm{Nd}_{2} \mathrm{Fe}_{14} \mathrm{~B}$ phase is sharp as shown in Fig. 4(a) with an abrupt change in Dy concentration near the core/shell interface as shown in the concentration depth profile in Fig. 4(f). In the case of solid state diffusion of Dy into the $\mathrm{Nd}_{2} \mathrm{Fe}_{14} \mathrm{~B}$ grains, the interface should have been diffused instead of being such a sharp one, indicating that the shell was not formed by the diffusion of Dy.

Fig. 5(a-d) shows STEM/EDS mapping near a grain boundary in the center of the sample that shows enrichment of Dy only in the grain to the right of the GB. Fig. 5(e) shows the concentration profile across the thin GB, where Nd-rich GB phase layer of several nanometers 
thickness is clearly observed. The left hand side of the GB is a $\mathrm{Nd}_{2} \mathrm{Fe}_{14} \mathrm{~B}$ grain. The right hand side of the $\mathrm{GB}$ is a $(\mathrm{Nd}, \mathrm{Dy}){ }_{2} \mathrm{Fe}_{14} \mathrm{~B}$ shell with an approximate thickness of $400 \mathrm{~nm}$. The average concentration of Dy in the shell (estimated from EDS using Dy $M \alpha$ ) is about 0.79 at.\%, which is much less than near the surface (1.35 at.\%). Importantly, it should be emphasized that the Dy enriched shell is present only on one-side of the GB. This strongly suggests that the Dy-rich shell was not formed by the solid state diffusion of Dy from GB to the grain interior, in which case Dy enriched shell should be present in both sides of the GB.

\subsection{Fraction of the oxide phases}

The fraction of $\mathrm{Nd}$ oxide phases is important for the current study as it can influence the phase fractions. In order to find out the fraction of metallic Nd-rich phase that is not oxidized, EDS maps of $\mathrm{O}$ and Nd were recorded. Fig. 6(a) shows oxygen map and Fig. 6(b) shows Nd map taken from the surface region. The oxide areas are highlighted in Fig. 6(c) with markers. The markers are copied onto Nd- map as shown in Fig. 6(d) to demonstrate the fraction of oxide areas out of all the Nd-rich phase. The areal fraction of Nd-rich triple junctions was $11 \%$ and the areal fraction of oxide was $2.4 \%$, indicating that about $8.6 \%$ areal fraction of Nd-rich phases is $\alpha-\mathrm{Nd}$, which is available to interact with the $\mathrm{Nd}_{2} \mathrm{Fe}_{14} \mathrm{~B}$ phase at high temperatures. Hence, the $\mathrm{Nd}$ oxide phases were not considered to influence the phase equilibrium substantially.

\section{Discussion}

As presented in Fig. 3(a), the microstructure in the vicinity of the surface consists of the faceted $\mathrm{Nd}_{2} \mathrm{Fe}_{14} \mathrm{~B}$ grains with thick $(\mathrm{Nd}, \mathrm{Dy})_{2} \mathrm{Fe}_{14} \mathrm{~B}$ shells, high fraction of the triple junction phase and the thick GB phase. In contrast, the center part consists of thin ( $\mathrm{Nd}, \mathrm{Dy})_{2} \mathrm{Fe}_{14} \mathrm{~B}$ shells, 
lower fraction of the triple junction phase and thin (but continuous) grain boundary phase as shown in Fig. 3(d). These results indicate that Nd-rich liquid phase was present during the diffusion process at the processing temperatures around $900{ }^{\circ} \mathrm{C}$. The observed faceting, the sharp interface between core and shell and the formation of Dy-free metallic Nd indicate that the shells were formed during solidification of the liquid phase instead of solid state diffusion.

To understand whether the shells originated due to solidification or diffusion, we performed thermodynamic calculations for each step of the diffusion process. Although the specimen contains various elements (Nd, $\mathrm{Pr}, \mathrm{Fe}, \mathrm{Co}, \mathrm{Dy}, \mathrm{Ga}, \mathrm{Cu}$ and $\mathrm{O}$ ), no thermodynamic database is available for the multi-component system. Moreover, thermodynamic data for $\operatorname{Pr}$ and $\mathrm{Ga}$ are not available. In order to reduce the complexity of the alloy system, the following assumptions were made; 1) Pr and Dy are considered as equivalent to $\mathrm{Nd}$, and Co as equivalent to $\mathrm{Fe}, 2$ ) oxygen is excluded because it forms very stable oxides, and 3) $\mathrm{Ga}$ and $\mathrm{Cu}$ are ignored because of their low concentration $(0.1$ at.\%). Thus, the alloy system is reduced to ternary $\mathrm{Nd}-\mathrm{Fe}-\mathrm{B}$ that is amenable to apply thermodynamic calculations. It results the reduced alloy composition of $14 \mathrm{Nd}-80 \mathrm{Fe}-6 \mathrm{~B}$ in at. $\%$. The Gibbs energy functions of the phases for thermodynamic calculations were taken from Hallemans et al. [22].

\subsection{Phase equilibrium during diffusion process}

The calculated transverse section of the Nd-Fe-B ternary system at the Fe/B ratio of 80/6 is presented in Fig. 7, where the concentration of the sample with 14 at.\% $\mathrm{Nd}$ is indicated as the solid line. Below the eutectic temperature, the microstructure consists of $\mathrm{Nd}_{2} \mathrm{Fe}_{14} \mathrm{~B}, \alpha-\mathrm{Nd}$ and $\mathrm{NdFe}_{4} \mathrm{~B}_{4}$ phases. As the temperature increases and reaches the eutectic temperature of $685{ }^{\circ} \mathrm{C}, \mathrm{Nd}_{2} \mathrm{Fe}_{14} \mathrm{~B}$ partially melts, and is in equilibrium with the Nd-rich liquid of the 
composition: Fe-67at.\%-7at.\%B. This eutectic reaction can be described as

$$
\mathrm{Nd}_{2} \mathrm{Fe}_{14} \mathrm{~B}+\alpha-\mathrm{Nd} \quad \leftrightarrow \quad \text { Liquid }+\mathrm{Nd}_{2} \mathrm{Fe}_{14} \mathrm{~B}
$$

where pure $\mathrm{Nd}$ liquefies $\mathrm{Nd}_{2} \mathrm{Fe}_{14} \mathrm{~B}$ at much lower temperatures $\left(685^{\circ} \mathrm{C}\right)$ than its original peritectic temperature around $1182{ }^{\circ} \mathrm{C}$. The eutectic reaction produces liquid at the $\mathrm{Nd} / \mathrm{Nd}_{2} \mathrm{Fe}_{14} \mathrm{~B}$ interfaces, i.e. triple junctions. Upon heating to the diffusion treatment temperature $\left(\sim 900^{\circ} \mathrm{C}\right)$, the fraction of liquid increases.

During the GBD process, Dy deposited in the form of vapor is dissolved in this liquid phase and modify the local composition near grain boundaries, increasing the concentration of Dy, which migrates from the surface to the central part of the specimen through grain boundaries. The composition of $\mathrm{RE}(=\mathrm{Nd}+\mathrm{Pr}+\mathrm{Dy})$ in the overall alloy shifts to the right in the pseudo-binary phase diagram as shown in Fig. 7. Following the lever rule at $900{ }^{\circ} \mathrm{C}$, the liquid phase should increase in quantity as the overall alloy composition shifts to RE-rich side. Fig. 8 shows the calculated fractions of various phases as a function of $\mathrm{Nd}$ content at $900{ }^{\circ} \mathrm{C}$. With increasing RE, the fraction of liquid phase increases linearly at the expense of $\mathrm{Nd}_{2} \mathrm{Fe}_{14} \mathrm{~B}$. This means the addition of Dy melts more $\mathrm{Nd}_{2} \mathrm{Fe}_{14} \mathrm{~B}$ phase due to the $\mathrm{Nd}_{2} \mathrm{Fe}_{14} \mathrm{~B}$ /liquid equilibrium. Table 2 shows the composition of the specimen near the surface estimated from SEM EDS analysis over a large region of $100 \mu \mathrm{m} \times 80 \mu \mathrm{m}$ area. Near the surface of the bulk sample, the total concentration of RE is about $14.7 \%$, which is slightly higher than the initial concentration of 14.2 at.\%, explaining the higher fraction of the Nd-rich phases near the surface of the sample treated by the GBD process.

\subsection{Shell formation during cooling}

Cooling of the Dy enriched liquid after diffusion processing leads to the formation of 
$\mathrm{Nd}_{2} \mathrm{Fe}_{14} \mathrm{~B} /(\mathrm{Nd}, \mathrm{Dy})_{2} \mathrm{Fe}_{14} \mathrm{~B}$ core/shell structure. At the processing temperature of $900^{\circ} \mathrm{C}$, $\mathrm{Nd}_{2} \mathrm{Fe}_{14} \mathrm{~B}$ crystals are embedded in a $\mathrm{Nd}(\mathrm{Dy})$-rich liquid phase. As the temperature decreases from $900{ }^{\circ} \mathrm{C}$, this Dy enriched liquid undergoes the following changes, (i) partial solidification into $(\mathrm{Nd}, \mathrm{Dy})_{2} \mathrm{Fe}_{14} \mathrm{~B}$ phases and (ii) continuous enrichment of rare earth in the liquid phase till ternary eutectic temperature $685^{\circ} \mathrm{C}$.

$$
\mathrm{Nd}(\mathrm{Dy}) \text {-rich liquid } \rightarrow(\mathrm{Nd}, \mathrm{Dy}){ }_{2} \mathrm{Fe}_{14} \mathrm{~B} \text { (shell) }+\mathrm{Nd}(\mathrm{Dy}) \text {-rich liquid }
$$

This transformation begins with the heterogeneous nucleation of $(\mathrm{Nd}, \mathrm{Dy})_{2} \mathrm{Fe}_{14} \mathrm{~B}$ on the existing $\mathrm{Nd}_{2} \mathrm{Fe}_{14} \mathrm{~B}$ grain facets, which act as platforms for solidifying shell from the surrounding liquid, thereby forming coherent but chemically abrupt interface. The heterogeneous nucleation is preferred because the energy barrier is much smaller than that of the homogeneous nucleation.

The shells grow as the temperature decreases further, all the way down to the eutectic temperature. At the ternary eutectic temperature, the remaining $\mathrm{Nd}(\mathrm{Dy})$-rich liquid phase transforms mainly into two phases as shown below.

$$
\text { Liquid } \rightarrow(\mathrm{Nd}, \mathrm{Dy})_{2} \mathrm{Fe}_{14} \mathrm{~B}+\alpha-\mathrm{Nd}(\mathrm{Dy})_{(\text {solid })}+(\mathrm{Nd}, \mathrm{Dy}) \mathrm{Fe}_{4} \mathrm{~B}_{4}
$$

The quantity of $(\mathrm{Nd}, \mathrm{Dy}) \mathrm{Fe}_{4} \mathrm{~B}_{4}$ is much less $(<1 \%)$ compared to that of the $(\mathrm{Nd}, \mathrm{Dy})_{2} \mathrm{Fe}_{14} \mathrm{~B}$ phase and $\alpha-(\mathrm{Nd}, \mathrm{Dy})$ solid phase. Based on the observations of EDS mapping from the surface, metallic $\mathrm{Nd}$ is formed without much Dy in it. From Table 1 , the ratio of $\mathrm{Dy} /(\mathrm{Nd}+\mathrm{Pr}+\mathrm{Dy})$ in the metallic Nd-rich phases is much less than that in the Nd-rich oxides and in the shells. This indicates that the Dy in the liquid phase is taken preferentially into the $(\mathrm{Nd}, \mathrm{Dy})_{2} \mathrm{Fe}_{14} \mathrm{~B}$ and $(\mathrm{Nd}, \mathrm{Dy}) \mathrm{O}_{\mathrm{x}}$ phases during the solidification. This preference of Dy towards $(\mathrm{Nd}, \mathrm{Dy}){ }_{2} \mathrm{Fe}_{14} \mathrm{~B}$ and (Nd,Dy) $\mathrm{O}_{\mathrm{x}}$ can be explained on the basis of thermodynamics. The Gibbs free energy change of formation of these rare-earth oxides are given with the expressions below [23]. 


$$
\begin{aligned}
& 2 \mathrm{Nd}+3 / 2 \mathrm{O}_{2}=\mathrm{Nd}_{2} \mathrm{O}_{3} \quad \Delta \mathrm{G}=-1798.769+0.2738 \mathrm{~T} \\
& 2 \mathrm{Dy}+3 / 2 \mathrm{O}_{2}=\mathrm{Dy}_{2} \mathrm{O}_{3} \quad \Delta \mathrm{G}=-1842.268+0.2735 \mathrm{~T}
\end{aligned}
$$

The temperature dependence of the two rare-earth elements is almost the same; hence essentially the Gibbs free energy of Dy-oxide is always lower than Nd-oxide making Dy oxide more stable than Nd-oxide. The formation energies of $\mathrm{Nd}_{2} \mathrm{Fe}_{14} \mathrm{~B}$ and $\mathrm{Dy}_{2} \mathrm{Fe}_{14} \mathrm{~B}$ phases calculated by the first principles were $-3.486 \mathrm{eV} / \mathrm{unit}$ and $-7.721 \mathrm{eV} / \mathrm{unit}$, respectively [24]. These values mean that the formation energy of the $\mathrm{Dy}_{2} \mathrm{Fe}_{14} \mathrm{~B}$ phase is more negative and hence it is energetically more favorable than $\mathrm{Nd}_{2} \mathrm{Fe}_{14} \mathrm{~B}$. From the above data, it is argued that Dy is preferentially partitioned in the $\mathrm{Nd}_{2} \mathrm{Fe}_{14} \mathrm{~B}$ and $\mathrm{NdO}_{\mathrm{x}}$ phases to form $(\mathrm{Nd}, \mathrm{Dy})_{2} \mathrm{Fe}_{14} \mathrm{~B}$ shell and $(\mathrm{Nd}, \mathrm{Dy}) \mathrm{O}_{\mathrm{x}}$ during the solidification of the (Nd,Dy)-rich liquid phase, leading to a relatively Dy-free $\alpha-\mathrm{Nd}$ phase at the eutectic point.

The amount of the shell $\left(=(\mathrm{Nd}, \mathrm{Dy})_{2} \mathrm{Fe}_{14} \mathrm{~B}\right.$ phase $)$ that can form during solidification can be estimated as follows. Fig. 9 shows the fraction of $\mathrm{Nd}_{2} \mathrm{Fe}_{14} \mathrm{~B}$ during cooling from $1200{ }^{\circ} \mathrm{C}$ for different compositions of $\mathrm{Nd}(=\mathrm{Nd}+\mathrm{Pr}+\mathrm{Dy})$, namely 14,17 and 20 at.\%. For the case of 14 at. $\% \mathrm{Nd}$, the amount of $\mathrm{Nd}_{2} \mathrm{Fe}_{14} \mathrm{~B}$ phase at the diffusion process temperature at $900{ }^{\circ} \mathrm{C}$ is $94.3 \%$, while the remaining amount is mostly Nd-rich liquid. Upon cooling to just below the eutectic temperature, the amount of $\mathrm{Nd}_{2} \mathrm{Fe}_{14} \mathrm{~B}$ phase increases to $96.7 \%$, and the liquid is transformed to metallic $\alpha-\mathrm{Nd}$. The amount of $\mathrm{Nd}_{2} \mathrm{Fe}_{14} \mathrm{~B}$ phase that is expected to form during cooling from $900{ }^{\circ} \mathrm{C}$ to the eutectic temperature is $96.7-94.3=2.4 \%$. Similarly, for 17 and $20 \mathrm{Nd}$ compositions, the quantities of shell that are formed during solidification are 5.7 and $9.1 \%$, respectively. In the present case, the total amount of RE observed experimentally was $14.7 \%$ (Table 2). By linear interpolation, the fraction of the shell that forms during solidification is estimated to be $3.1 \%$. The observed quantity of the shell was about $6-15 \%$, 
which is much higher than the calculated shell area. This difference can be explained on the basis of the presence of the minor alloying elements in the magnets such as $\mathrm{Co}, \mathrm{Cu}$, and $\mathrm{Ga}$. These elements can form low-melting eutectic reactions with $\mathrm{Nd}$ [25] and possibly increase the quantity of the liquid phase, although the exact interactions between these elements and $\mathrm{Nd}_{2} \mathrm{Fe}_{14} \mathrm{~B}$ phase are not known.

The most common traces of the faceted interfaces observed in this study were $\langle 100\rangle,\langle 001\rangle$, and $\langle 011\rangle$ in c-axis in-plane view and $\langle 100\rangle$ in c-axis out-of-plane view. This means that these indices represent core-shell interfaces that have specific crystallographic planes. In c-axis in-plane view, two-dimensional projection of the cross-section of either (001) or (011) plane appears as [100] direction for aligned grains. In other words, [100] direction could represent either of the planes (001) or (011) if only these fundamental low-index planes are considered. Similarly, [10 $\overline{1}]$ direction could represent either (101) or (111) planes. All such possible low index planes from the sets of directions are given in Table 3. A schematic of reconstruction of a $\mathrm{Nd}_{2} \mathrm{Fe}_{14} \mathrm{~B}$ core with the discussed facet planes just before solidification is shown in Fig. 10. It is likely that these low index planes offer the minimum energy configuration in the $\mathrm{Nd}_{2} \mathrm{Fe}_{14} \mathrm{~B}$ /liquid equilibrium. During cooling, the (Nd,Dy) ${ }_{2} \mathrm{Fe}_{14} \mathrm{~B}$ shell grow from these faceted planes. Upon cooling, these shells grow steadily and impinge to their neighboring grains. If the $(\mathrm{Nd}, \mathrm{Dy})_{2} \mathrm{Fe}_{14} \mathrm{~B}$ shell does not grow from the neighboring grains, the impinged interface will have a shell only on one side, and the other is $\mathrm{Nd}_{2} \mathrm{Fe}_{14} \mathrm{~B}$ grain. This is why the many shells are along one-side of the GBs rather than along both the sides.

The EBSD orientation maps show that there is no misorientation between shells and cores. This result is reasonable as the $(\mathrm{Nd}, \mathrm{Dy})_{2} \mathrm{Fe}_{14} \mathrm{~B}$ shell grow from the $\mathrm{Nd}_{2} \mathrm{Fe}_{14} \mathrm{~B}$ core during 
solidification. The difference in the atomic radii between $\mathrm{Nd}(0.185 \mathrm{~nm})$ and $\mathrm{Dy}(0.175 \mathrm{~nm})$ is about $5.5 \%$, while the difference in the lattice parameters of $\mathrm{Nd}_{2} \mathrm{Fe}_{14} \mathrm{~B}(\mathrm{a}=0.8808 \mathrm{~nm}$ and $\mathrm{c}=$ $1.2207 \mathrm{~nm})[26]$ and $\mathrm{Dy}_{2} \mathrm{Fe}_{14} \mathrm{~B}(\mathrm{a}=0.8754 \mathrm{~nm}$, and $\mathrm{c}=1.1977 \mathrm{~nm})$ [27] is only about $1-2 \%$. The Dy composition of the (Nd,Dy) ${ }_{2} \mathrm{Fe}_{14} \mathrm{~B}$ shells, obtained from the EDS results is about 1.4 at.\% while the stoichiometric composition of $\mathrm{Nd}$ in $\mathrm{Nd}_{2} \mathrm{Fe}_{14} \mathrm{~B}$ is 11.8 at.\%. Hence the partial substitution of $\mathrm{Nd}$ with Dy (1.4 out of $11.8 \%$ ) is expected to cause only a negligible difference of the lattice size. Thus, it is possible for the $(\mathrm{Nd}, \mathrm{Dy})_{2} \mathrm{Fe}_{14} \mathrm{~B}$ shell to form in a fully coherent manner with the $\mathrm{Nd}_{2} \mathrm{Fe}_{14} \mathrm{~B}$ core.

Fig. 11 shows the summary of the mechanism of the shell structure formation. Fig. 11(a) shows a typical sintered magnet microstructure schematically. It has $\mathrm{Nd}_{2} \mathrm{Fe}_{14} \mathrm{~B}$ phase, and metallic Nd-rich phases. Upon heating to ternary eutectic temperature, the Nd-rich liquid starts to appear, whose quantity increases upon heating further to diffusion processing temperature. Now the phases present are $\mathrm{Nd}_{2} \mathrm{Fe}_{14} \mathrm{~B}$, oxide and Nd-rich liquid (Fig. 11(b)). Upon Dy addition as part of the diffusion process, the liquid gets enriched in Dy and the quantity of the liquid phase increases further as shown in Fig. 11(c). Finally after cooling, the Dy-enriched liquid solidifies into (Nd,Dy) ${ }_{2} \mathrm{Fe}_{14} \mathrm{~B}$ shell as shown in Fig. $11(\mathrm{~d})$ on the existing $\mathrm{Nd}_{2} \mathrm{Fe}_{14} \mathrm{~B}$ grains with the core-shell facets in a coherent manner.

\subsection{Magnetic Properties}

It is postulated that the concentration of Dy near the GB regions (shells) is more important than that in the entire grain for coercivity. Hence, the presence of Dy in the form of shells is enough to enhance coercivity instead of being in the entire bulk. In this study, the relation between the Dy concentration in the shells and the coercivity is evaluated. EDS 
analysis has shown that the average concentration of Dy in the shells is about 1.35 at.\% near the surface of the bulk sample, and about 0.79 at.\% near the center. The overall average concentration of Dy in the shells is then $(1.35+0.79) / 2=1.07$ at.\%, compared to that of the untreated magnet of 0.20 at.\%. The anisotropy field of $\mathrm{Nd}_{2} \mathrm{Fe}_{14} \mathrm{~B}$ is $7.7 \mathrm{~T}$ [28], while that of $\mathrm{Dy}_{2} \mathrm{Fe}_{14} \mathrm{~B}$ is $15.0 \mathrm{~T}$ [29]. Hence the anisotropy field of the magnet with 1.07 at.\% Dy containing shells (of composition $\sim\left(\mathrm{Nd}_{0.9} \mathrm{Dy}_{0.1}\right)_{2} \mathrm{Fe}_{14} \mathrm{~B}$ ) becomes $\sim 8.4 \mathrm{~T}$. This increased anisotropy field results in an increased coercivity of the magnet due to the impediment of nucleation of the reversal magnetic domains.

The coercivity of the magnet after the diffusion process was $2.0 \mathrm{~T}$. To obtain the same $2 \mathrm{~T}$ coercivity in the commercial Nd-Dy-Fe-B sintered magnets, the amount of Dy needed is about 5 wt.\% or 2 at.\% Dy [2]. The overall Dy content in the shells of the diffusion processed magnet is 1.07 at $\%$, which is only $54 \%$ (about half) of the required concentration to reach $2 \mathrm{~T}$ coercivity. The remaining $46 \%$ contribution to the coercivity could be attributed to the presence of the GB phase as discussed by Sepehri-Amin et al. [8].

\section{Summary}

Detailed microstructural characterization and thermodynamic phase equilibrium calculations were carried out on grain boundary diffusion processed commercial sintered magnet produced by the Dy vapor deposition method. The core-shell interfaces were faceted with $\{001\},\{111\},\{011\}$, and $\{100\}$ planes, suggesting the formation of the core/shell structure during solidification from the diffusion process temperature. Partial melting of the $\mathrm{Nd}_{2} \mathrm{Fe}_{14} \mathrm{~B}$ phase at the process temperature leads to the formation the faceted $\mathrm{Nd}_{2} \mathrm{Fe}_{14} \mathrm{~B}$ cores, and the solidification of the Dy enriched liquid results in the formation of the $(\mathrm{Nd}, \mathrm{Dy})_{2} \mathrm{Fe}_{14} \mathrm{~B}$ 
shell with coherent core-shell interface. The RE concentration near the surface is increased due to Dy addition in the form of vapor, resulting in the higher areal fraction of the triple junction phases and thicker grain boundary phase near the surface. $\mathrm{Nd}$ in $\mathrm{Nd}$-oxide phases is substituted with Dy during the diffusion process due to strong affinity of Dy with oxygen. The average concentration of Dy in the shells is 1.07 at.\%, thereby increasing the anisotropy field of the shells. The presence of thick GB phase near the surface is also attributed to the improved coercivity of the magnet. Although a higher concentration of Dy in the shells is required for further increase of coercivity, GBD process will not be able to achieve it since the Dy concentration in the shell is mainly determined by the $\mathrm{Nd}_{2} \mathrm{Fe}_{14} \mathrm{~B}$ /liquid equilibrium.

\section{Acknowledgments}

This work is in part supported by Japan Science and Technology Agency, CREST. The samples for analysis were provided by Toyota Corporation, Japan. 


\section{References}

[1] M. Sagawa, S. Fujimura, N. Togawa, H. Yamamoto, Y. Matsuura, J. Appl. Phys., 55 (1984) 2083.

[2] K. Hono, H. Sepehri-Amin, Scr. Mater., 67 (2012) 530.

[3] K. Park, K. Hiraga, M. Sagawa, in: Proceedings of the Sixteenth International Workshop on Rare-Earth Magnets and Their Applications, Sendai, 2000, pp. 257.

[4] H. Nakamura, K. Hirota, M. Shimao, T. Minowa, M. Honshima, IEEE Trans. Magn., 41 (2005) 3844.

[5] K. Hirota, H. Nakamura, T. Minowa, M. Honshima, IEEE Trans. Magn., 42 (2006) 2909.

[6] D. Li, S. Suzuki, T. Kawasaki, K. Machida, Japanese J. Appl. Phys., 47 (2008) 7876.

[7] H. Nakamura, Materia Japan, 50 (2011) 374.

[8] H. Sepehri-Amin, T. Ohkubo, K. Hono, Acta Mater., 61 (2013) 1982.

[9] Z. Samardžija, P. McGuiness, M. Soderžnik, S. Kobe, M. Sagawa, Mater. Charact., 67 (2012) 27.

[10] N. Watanabe, M. Itakura, N. Kuwano, D. Li, S. Suzuki, K. Machida, Mater. Trans., 48 (2007) 915.

[11] D.S. Li, S. Suzuki, W.F. Liu, T. Horikawa, K. Machida, IOP Conference Series: Mater. Sci. Eng., 1 (2009) 012019

[12] D.S. Li, M. Nishimoto, S. Suzuki, K. Nishiyama, M. Itoh, K. Machida, IOP Conference Series: Mater. Sci. Eng., 1 (2009) 012020.

[13] H. Suzuki, Y. Satsu, M. Komuro, J. Appl. Phys., 105 (2009) 07A734-733.

[14] G. Yan, P.J. McGuiness, J.P.G. Farr, I.R. Harris, J. Alloys and Comp., 491 (2010) L20.

[15] H. Nakamura, K. Hirota, T. Ohashi, T. Minowa, J. Phys. D: Appl. Phys., 44 (2011) 064003.

[16] N. Oono, M. Sagawa, R. Kasada, H. Matsui, A. Kimura, J. Magn. Magn. Mater., 323 (2011) 297.

[17] K.H. Bae, T.H. Kim, S.R. Lee, S. NamKung, T.S. Jang, IEEE Trans. Magn., 49 (2013) 3251.

[18] A.G. Popov, D.Y. Vasilenko, T.Z. Puzanova, A.V. Shitov, A.V. Vlasyuga, The Physics of Metals and Metallography, 111 (2011) 471.

[19] K. Khlopkov, O. Gutfleisch, D. Eckert, D. Hinz, B. Wall, W. Rodewald, K.H. Müller, L. Schultz, J. of Alloys and Comp., 365 (2004) 259-265.

[20] T.G. Woodcock, O. Gutfleisch, Acta Mater., 59 (2011) 1026-1036.

[21] W.F. Li, H. Sepehri-Amin, T. Ohkubo, N. Hase, K. Hono, Acta Mater., 59 (2011) 3061.

[22] B. Hallemans, P. Wollants, J.R. Roos, J. Phase Equil., 16 (1995) 137.

[23] G. Adachi, N. Imanaka, Chem. Rev., 98 (1998) 1479.

[24] Hao Hong-Fei, Wang Jing, Sun Feng, Zhang Lan-Ting, Acta Phys. Sinica, 62 (2013) 117501.

[25] H. Baker, H. Okamoto, Ed. ASM Metals Handbook, Vol.3: Alloy Phase Diagrams 2nd edition, ASM International, Materials Park, OH, USA (1992)

[26] C. Chacon, O. Isnard, E. Suard, J. Alloys Comp., 317-318 (2001) 60.

[27] L.Y. Zhang, F. Pourarian, W.E. Wallace, J. Magn. Magn. Mater., 71 (1988) 203.

[28] J.M. Coey, Magnetism and Magnetic Materials, Cambridge University Press, UK. 2010.

[29] S. Hirosawa, Y. Matsuura, H. Yamamoto, S. Fujimura, M. Sagawa, H. Yamauchi, J. Appl. Phys., 59 (1986) 873. 


\section{List of Figures}
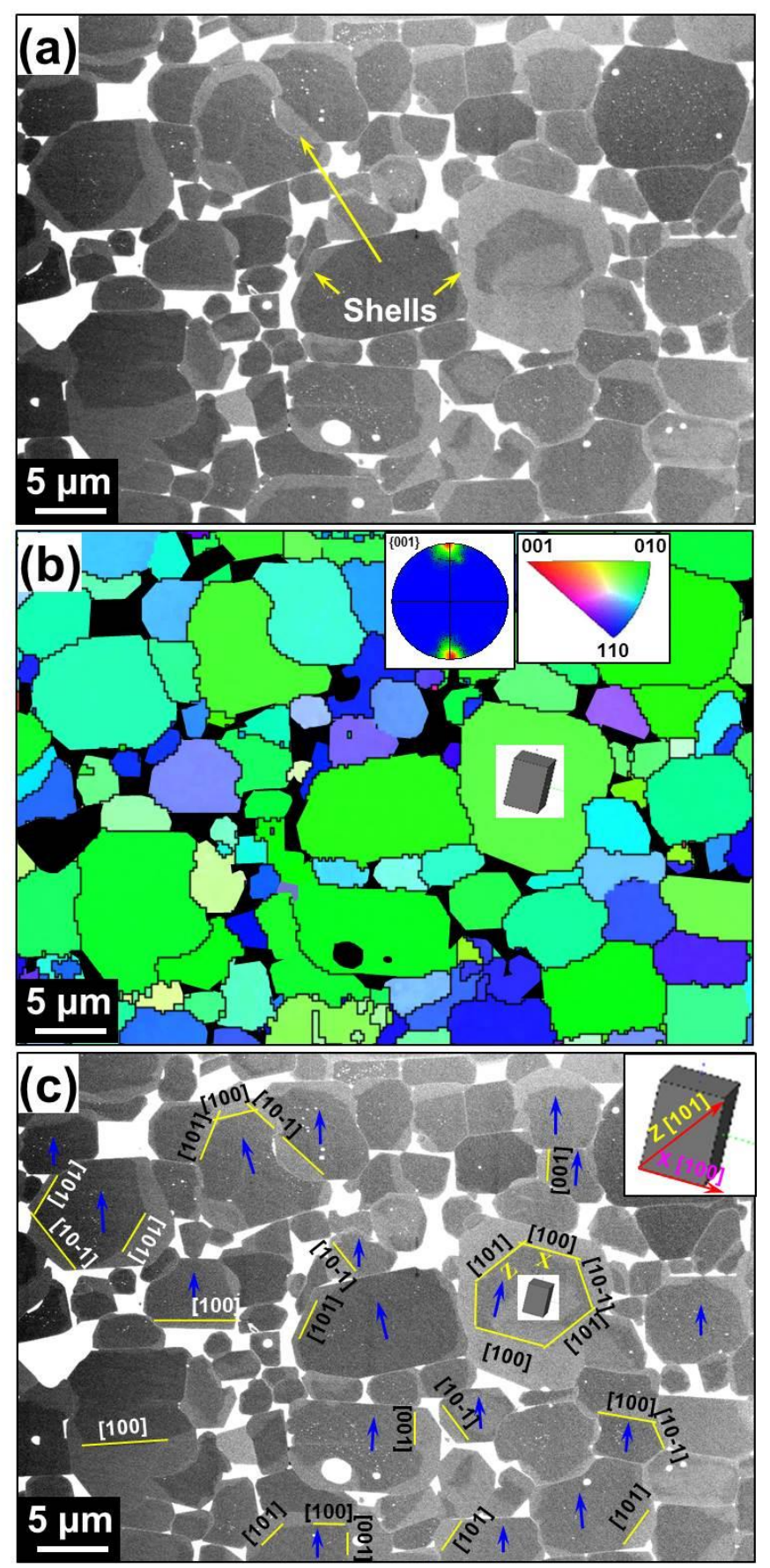

Fig. 1. (a) BSE micrograph of GBDP sintered Nd-Fe-B magnet (c-axis in-plane); this micrograph highlights the core/shell structure with faceting of the shells (b) EBSD grain mapping from the same region; Nd-rich phases are marked black color. The two insets show $\{001\}$ pole figure and color index. (c) Indexing of the grains in image (a); blue arrows indicate c-axis directions and yellow lines represent faceting planes 

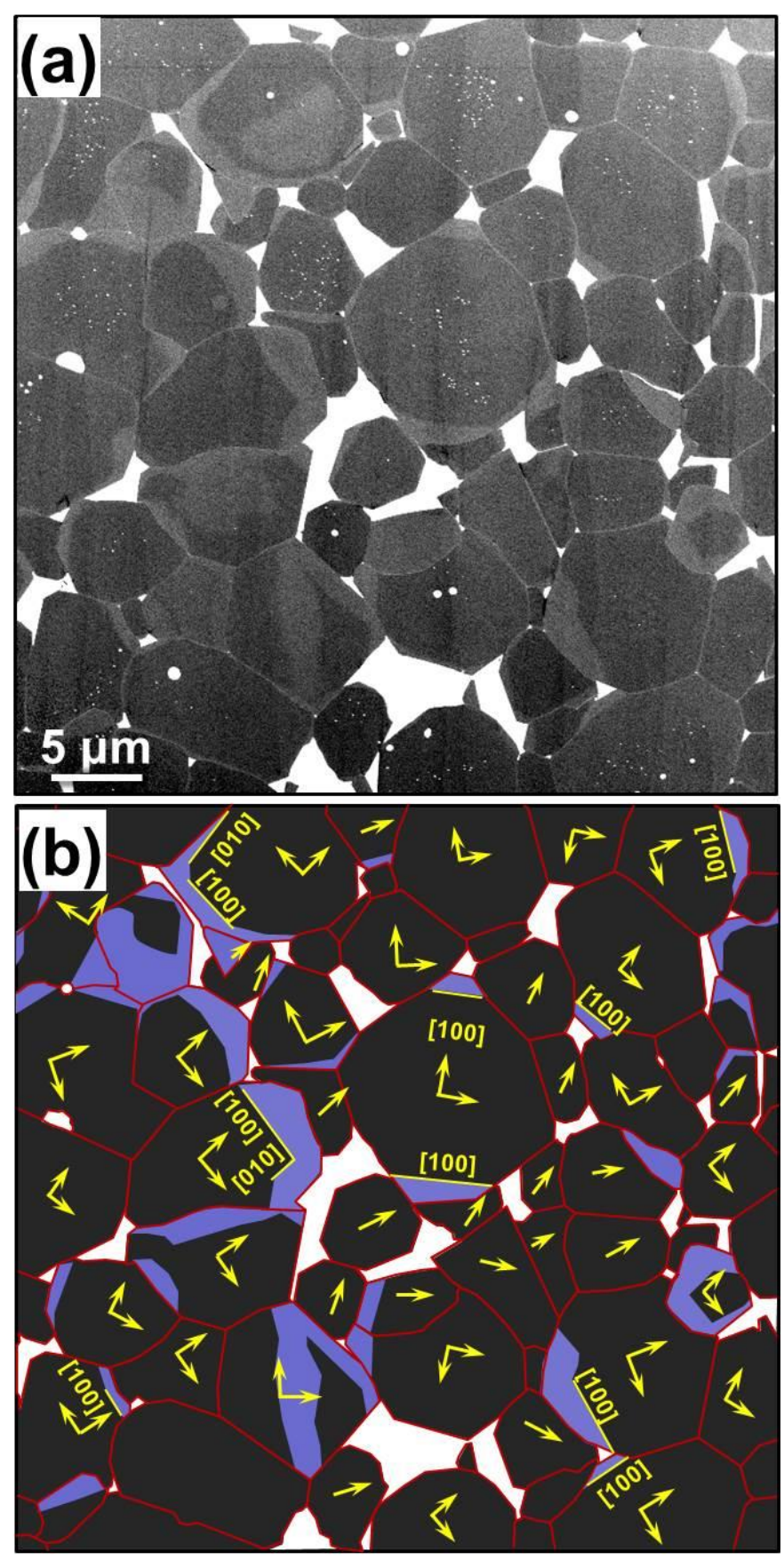

Fig. 2. (a) BSE micrograph of the same magnet with c-axis out-of-plane; the core/shell structure with faceting is evident. (b) Tracing of Fig. 2(a) that clearly shows distribution of shell structure. Indexing of the facet interfaces is also marked after EBSD orientation analysis. Yellow arrows indicate $a-a x i s$ and $b$-axis directions and yellow lines represent faceting planes. 


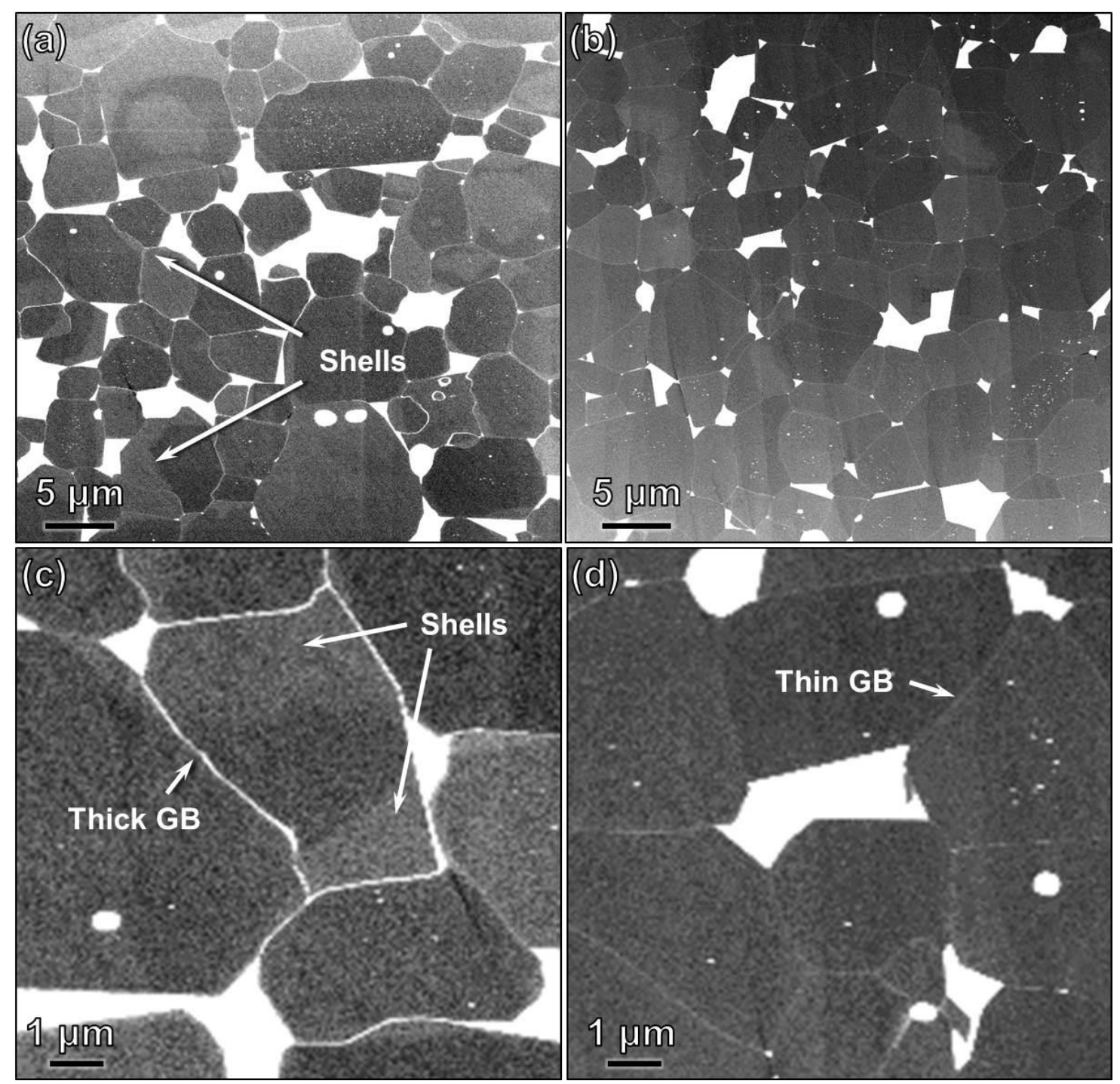

Fig. 3. Lower magnification surface (a) shows higher triple junction phase and thicker grain boundary than at the center (b). Higher magnification surface (c) and center (d) highlight the features 

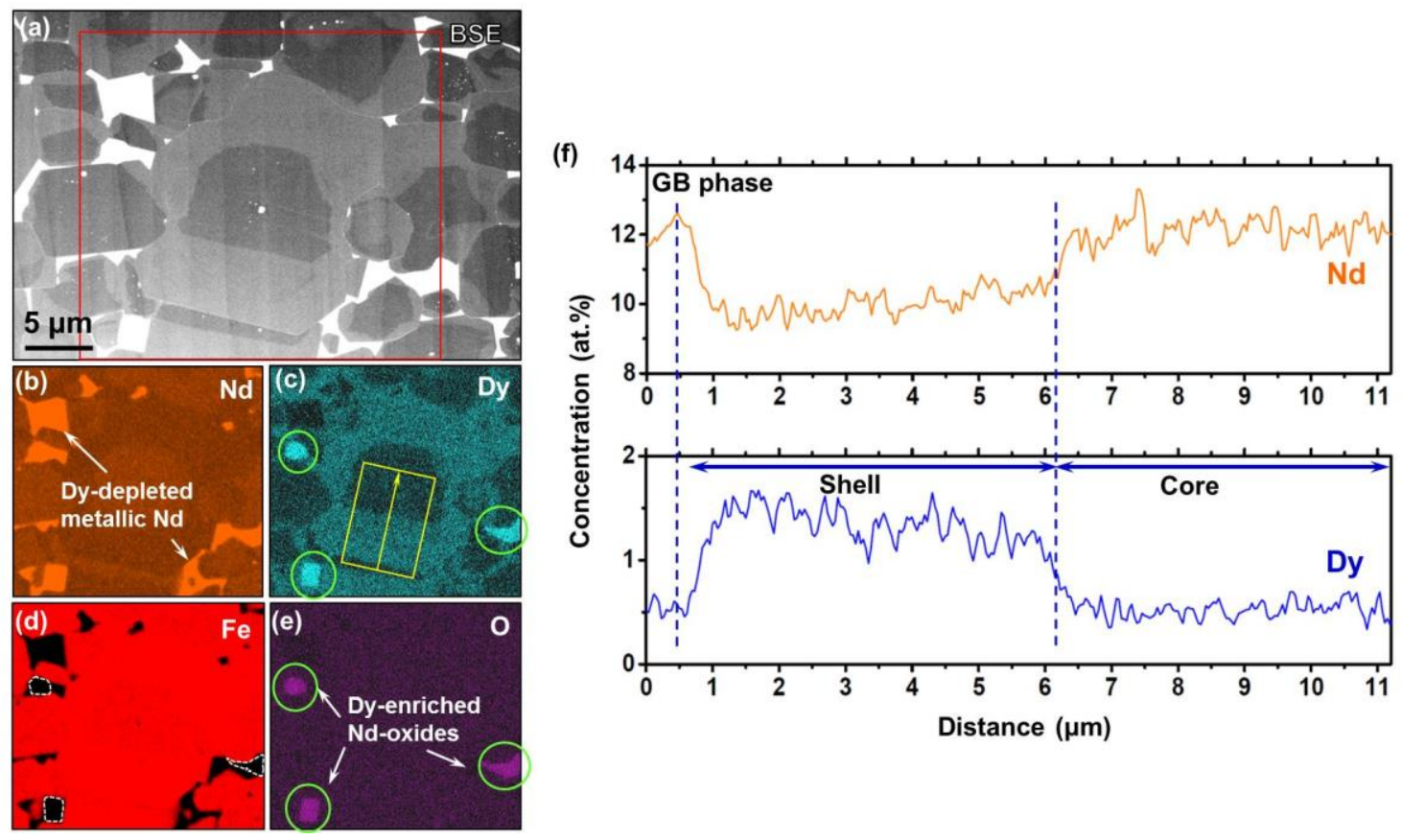

Fig. 4. BSE micrograph and EDS elemental maps from a thick core/shell structure. The rectangle in (a) BSE micrograph is the selected area for EDS mapping shown in (b-e). Nd La, Dy M $\alpha, \mathrm{Fe} \mathrm{K} \alpha$, and O K $\alpha$ were used to quantify EDS spectra. The circles in (c) and (e), the dotted lines in (d) show the areas of Dy-enriched Nd-oxides. (f) shows $\mathrm{Nd}$ and $\mathrm{Dy}$ concentration profiles across the selected line shown in (c). Note that there is a sudden change in the concentration across the core/shell interface. 

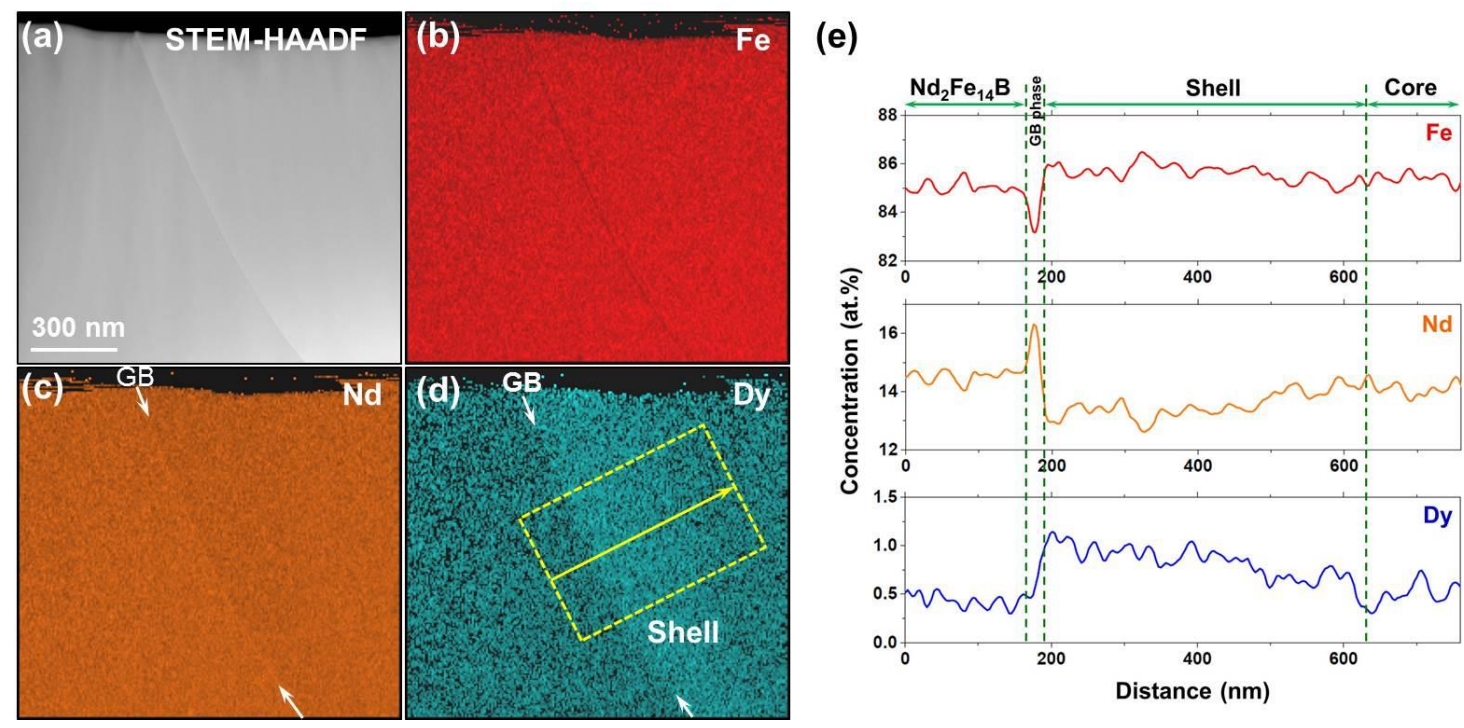

Fig. 5. STEM/EDS mapping of a region containing a grain boundary and shell. (b-d) show elemental maps of Fe, $\mathrm{Nd}$ and Dy. Dy enrichment was observed only on side of the grain boundary as shown. Concentration profile across the grain boundary and shell that are shown in Fig. 5(e). Dy is enriched on the right of the GB phase 


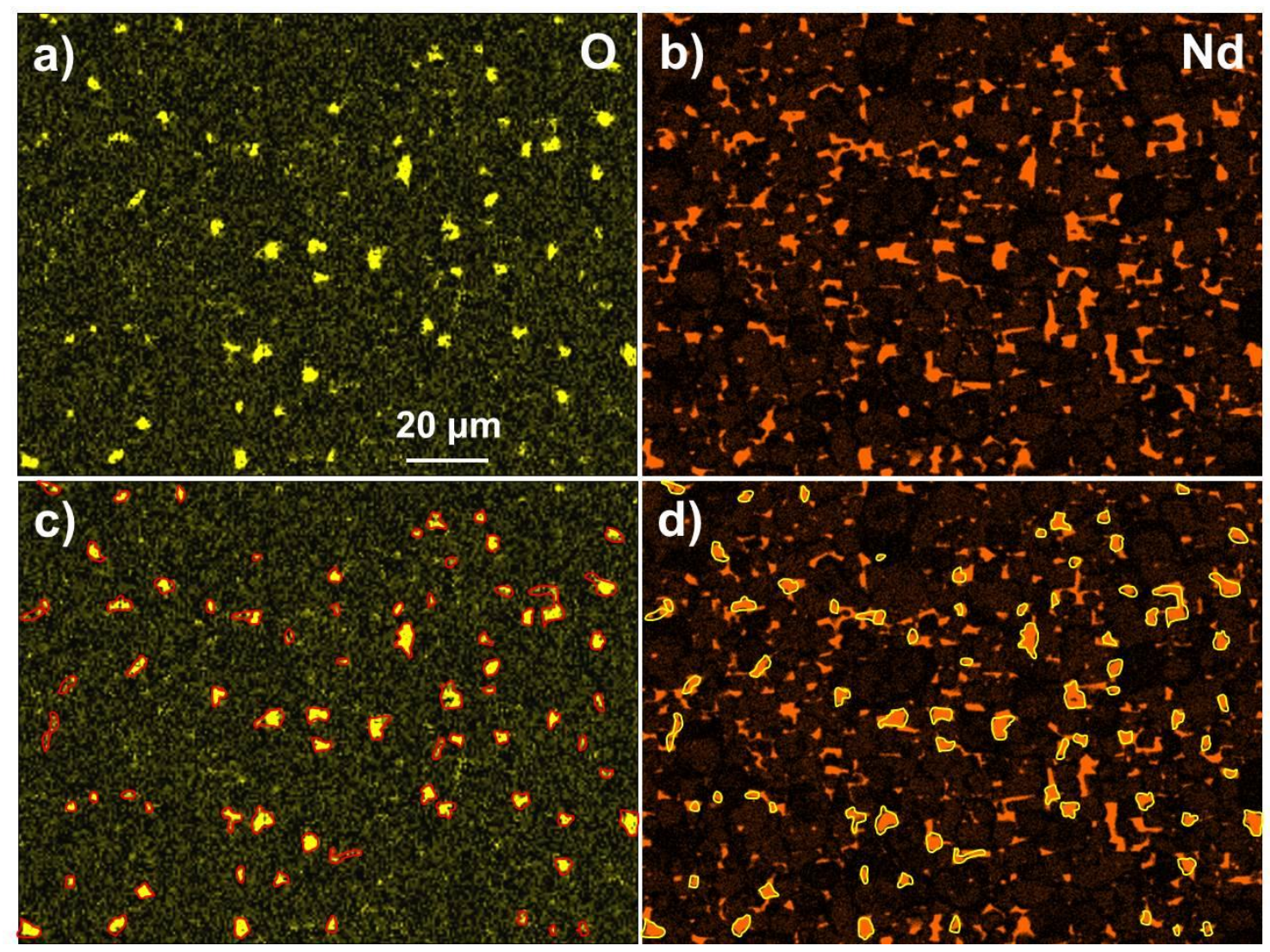

Fig. 6. EDS maps of oxygen (a) and Nd (b) from the surface of the magnet. Bright areas correspond to Nd-rich phase. It is clear that only a portion of the Nd-rich areas is rich in oxygen, which is identified as $\mathrm{NdO}_{\mathrm{x}}$. Such oxide regions in (c) are marked using outlines, which are replicated in (d) on the Nd-rich regions to show oxide portions. Two parts of the Nd-rich phases, (i) metallic $\mathrm{Nd}$ and (ii) Nd-rich oxides are observed. 


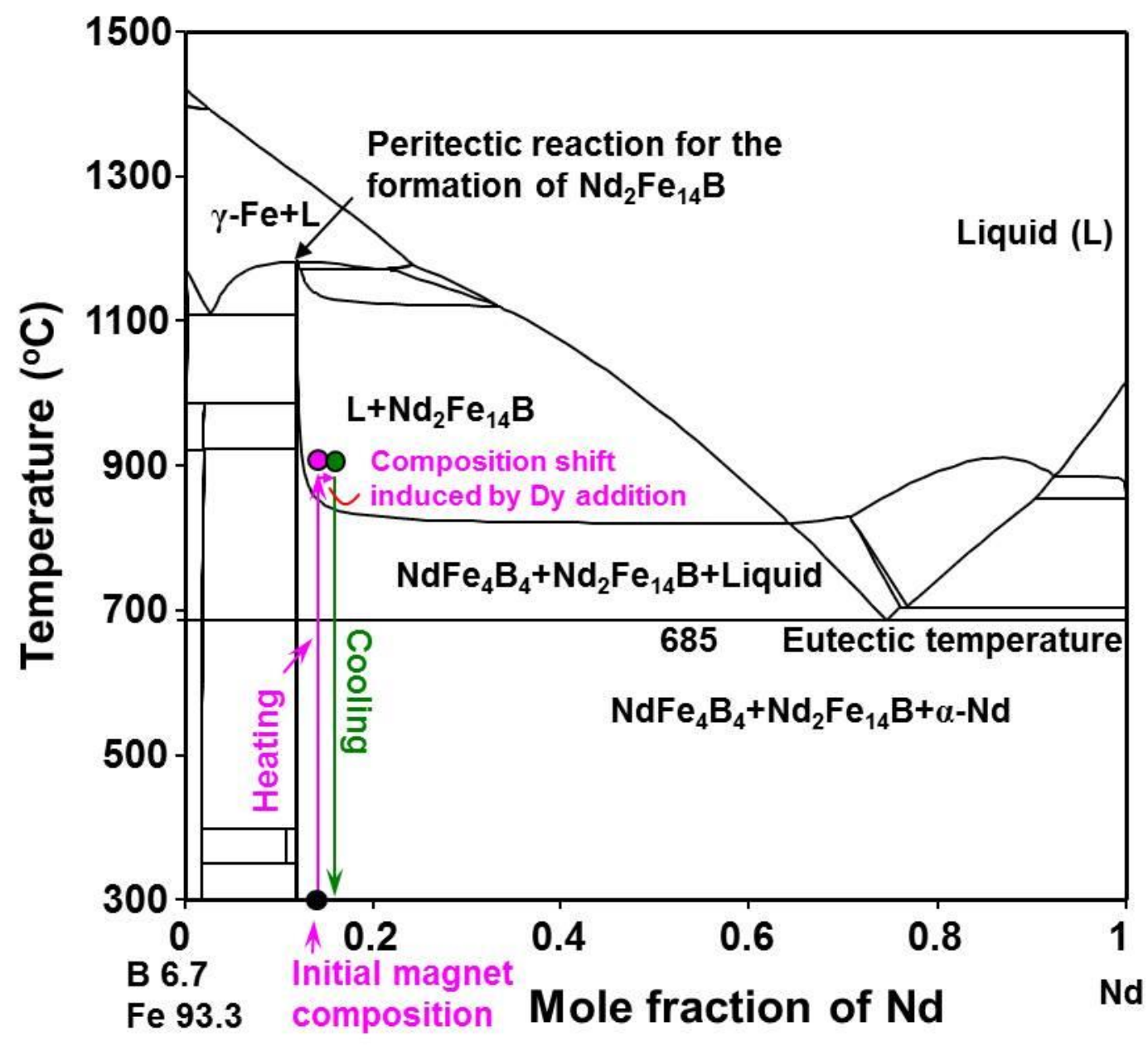

Fig. 7. Calculated pseudo-binary phase diagram of Nd-Fe-B at Fe/B ratio of 14 . The initial composition of the total rare-earth is $14.20 \%$ and after diffusion process, it is increased to about $14.69 \%$. This is due to the addition of Dy as indicated by the horizontal arrow at $900{ }^{\circ} \mathrm{C}$. 


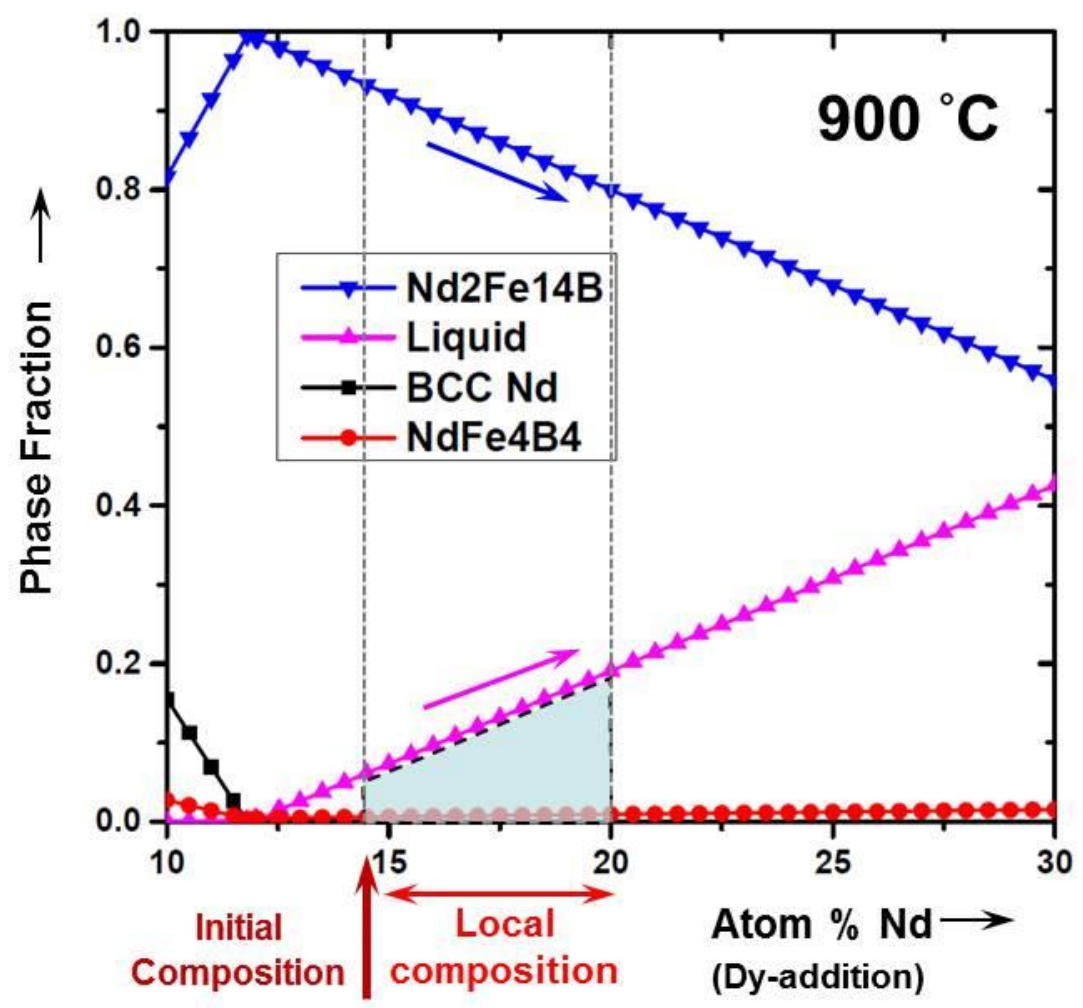

Fig. 8. Phase fractions of ternary Nd-Fe-B alloys with respect to different Nd contents. Note that with increased $\mathrm{Nd}(\mathrm{Dy})$ content in the overall alloy, fraction of the liquid phase increases and the amount of $\mathrm{Nd}_{2} \mathrm{Fe}_{14} \mathrm{~B}$ phase decreases, as observed experimentally. 


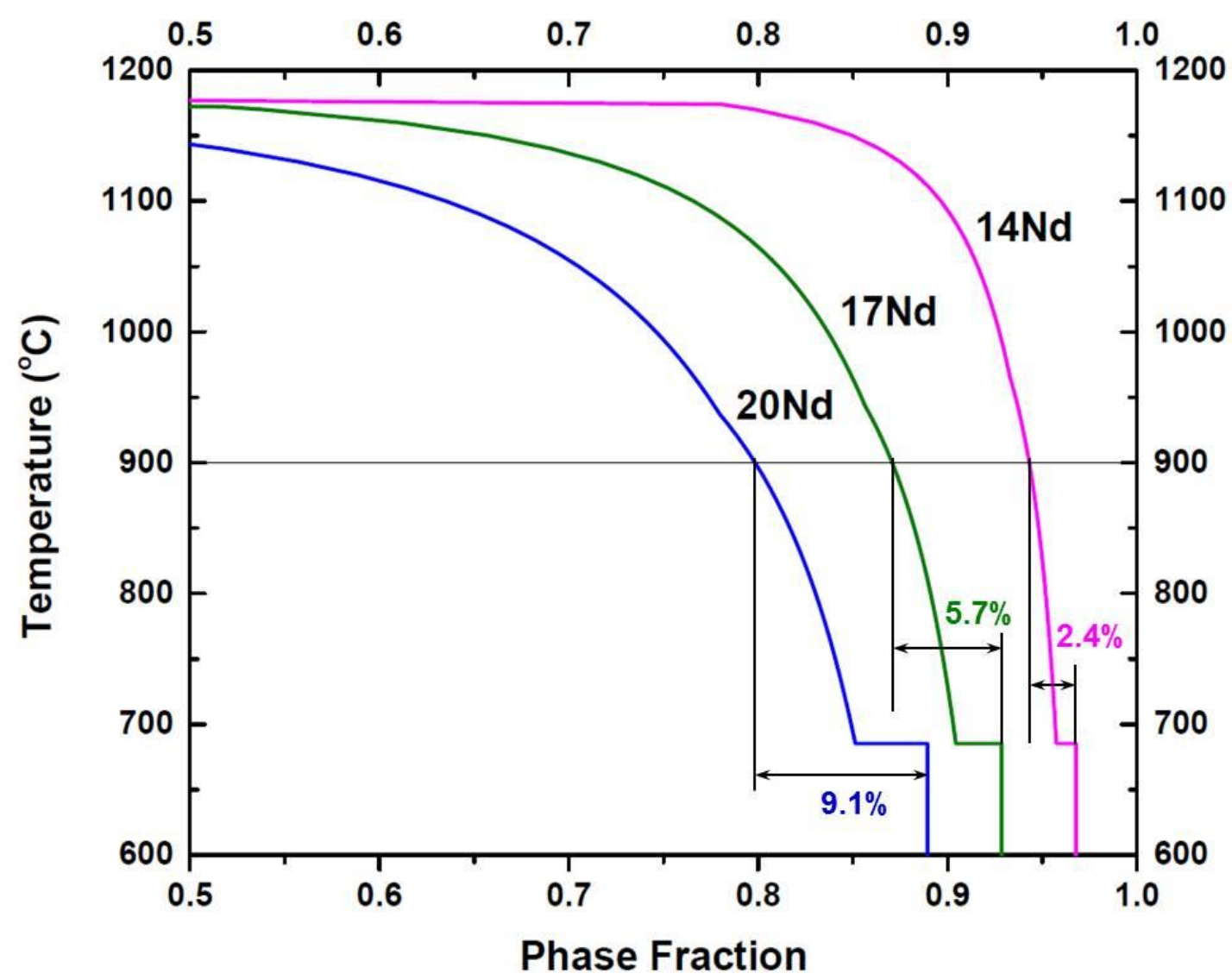

Fig. 9. $\mathrm{Nd}_{2} \mathrm{Fe}_{14} \mathrm{~B}$ phase fractions at different temperatures for the 14,17 and 20 at. $\% \mathrm{Nd}$. The quantity of $\mathrm{Nd}_{2} \mathrm{Fe}_{14} \mathrm{~B}$ phase that can form during cooling from $900{ }^{\circ} \mathrm{C}$ to eutectic temperature is $2.3,5.7$ and $8 \%$ respectively.

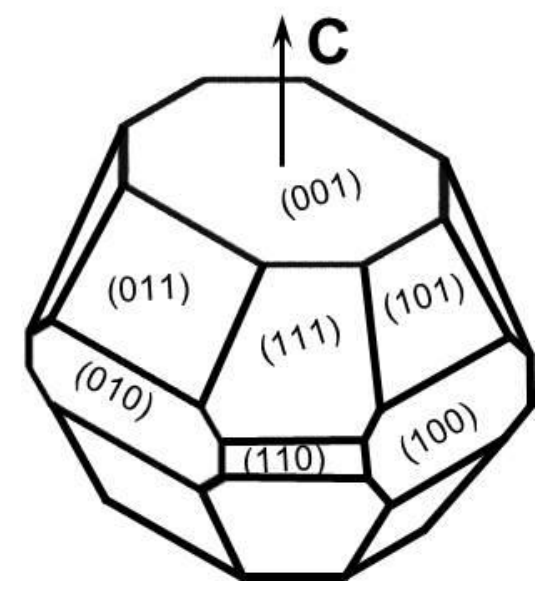

Fig. 10. Schematic representation of a typical $\mathrm{Nd}_{2} \mathrm{Fe}_{14} \mathrm{~B}$ grain core with different facet planes 
(a) Room temperature; untreated

(b) $\sim 900^{\circ} \mathrm{C}$; before GBDP
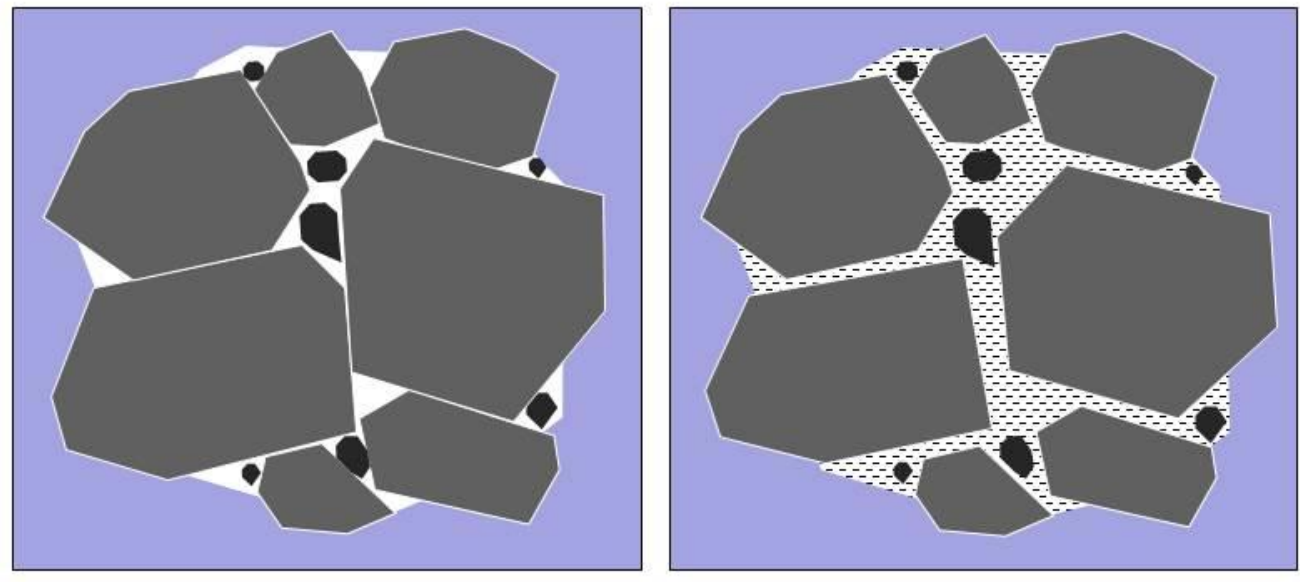

(c) $\sim 900{ }^{\circ} \mathrm{C}$; after Dy addition

(d) RT; after solidification
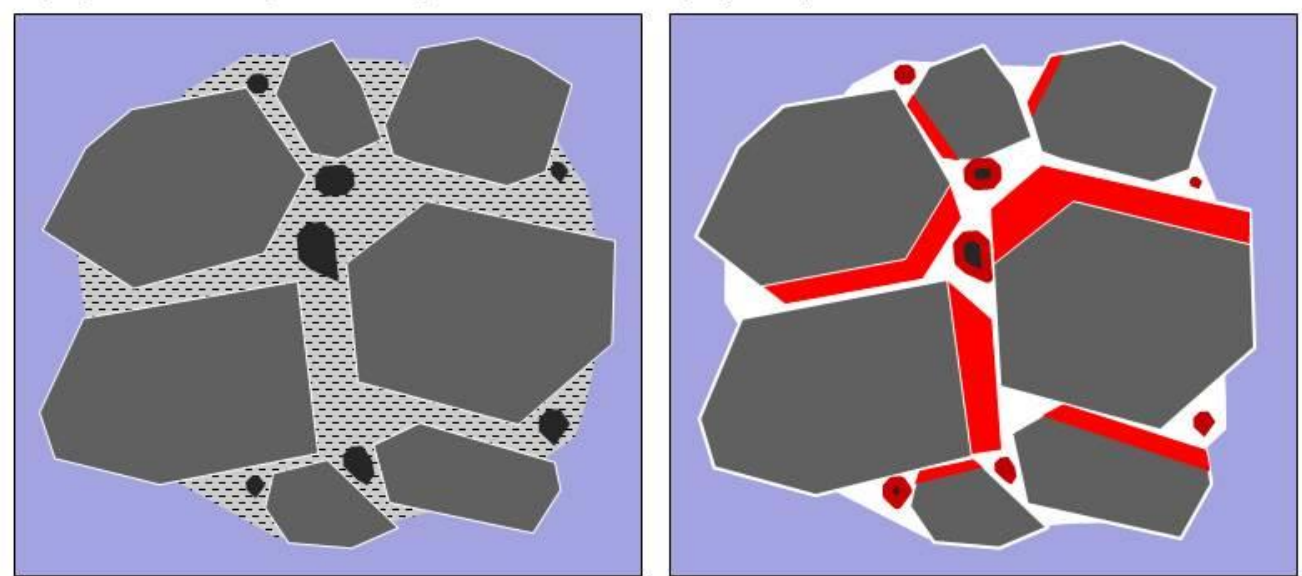

Liquid $\rightarrow(\mathrm{Nd}, \mathrm{Dy})_{2} \mathrm{Fe}_{14} \mathrm{~B}($ Shell $)+$ Metallic $\mathrm{Nd}$

$\mathrm{Nd}_{2} \mathrm{Fe}_{14} \mathrm{~B}$

$\square$ Metallic $\mathrm{Nd}$

$\square \mathrm{NdO}_{\mathrm{x}}$

Nd-rich liquid $\mathrm{Nd}$,Dy-rich liquid

Shell

$(\mathrm{Nd}, \mathrm{Dy}) \mathrm{O}_{\mathrm{x}}$

Fig. 11. Schematic representation of the mechanism of the shell structure formation 


\section{List of Tables}

Table 1. Concentration of elements obtained from EDS and comparison of Dy/(Nd+Pr+Dy) ratio in different phases (Given in the brackets are the standard deviation values for the concentration of the respective elements)

\begin{tabular}{|l|l|l|l|l|l|l|}
\hline Phase & \multicolumn{5}{|c|}{ Concentration of elements (atom \%) } & \\
\hline & $\begin{array}{c}\mathrm{Dy} \\
\left(\mathrm{M}_{\alpha}\right)\end{array}$ & $\begin{array}{c}\mathrm{Nd}+\mathrm{Pr} \\
\left(\mathrm{L}_{\alpha}\right)\end{array}$ & $\begin{array}{c}\mathrm{Fe} \\
\left(\mathrm{K}_{\alpha}\right)\end{array}$ & $\begin{array}{c}\mathrm{O} \\
\left(\mathrm{K}_{\alpha}\right)\end{array}$ & $\mathrm{Nd+Pr+Dy}$ & $\begin{array}{c}\text { Dy/(Nd+Pr+Dy) } \\
\text { Ratio }\end{array}$ \\
\hline $\begin{array}{l}(\mathrm{Nd}, \mathrm{Dy})_{2} \mathrm{Fe}_{14} \mathrm{~B} \\
\text { shell }\end{array}$ & 1.35 & 10.45 & 88.20 & & & \\
\hline Metallic & $(0.16)$ & $(0.37)$ & $(0.31)$ & - & 11.80 & 0.1144 \\
Nd-rich phase & $(0.50$ & 92.50 & 6.00 & 1.00 & & \\
\hline & $6.22)$ & $(3.17)$ & $(2.85)$ & $(0.66)$ & 93.00 & 0.0054 \\
$(\mathrm{Nd}, \mathrm{Dy})-$ oxide & $(0.55)$ & 45.80 & 6.50 & 33.00 & & \\
\hline
\end{tabular}

Table 2. Composition of the magnet at $\sim 50 \mu \mathrm{m}$ from its surface after diffusion processing. It was obtained by EDS mapping a large region of $100 \mu \mathrm{m}$ x $80 \mu \mathrm{m}$. (Given in the brackets are the standard deviation values for the concentration of the respective elements)

\begin{tabular}{|c|c|}
\hline Overall surface composition & $\begin{array}{c}\text { Atom \% (EDS) - } \\
\text { excluding Boron }\end{array}$ \\
\hline $\mathrm{Nd}\left(\mathrm{L}_{\alpha}\right)$ & $10.94(0.83)$ \\
\hline $\operatorname{Pr}\left(\mathrm{L}_{\alpha}\right)$ & $3.67(0.30)$ \\
\hline $\mathrm{Fe}\left(\mathrm{K}_{\alpha}\right)$ & $84.42(6.06)$ \\
\hline $\mathrm{Dy}\left(\mathrm{M}_{\alpha}\right)$ & $0.97(0.13)$ \\
\hline Total RE $(\mathrm{Nd}+\mathrm{Pr}+\mathrm{Dy})$ & 15.58 \\
\hline $\begin{array}{c}\text { Total RE after correcting for } \\
\text { Boron } \\
(5.7 \% \text { reduction })\end{array}$ & 14.69 \\
\hline
\end{tabular}

Table 3. Possible set of planes from the traces $\langle 100\rangle,\langle 011\rangle$ c-axis in the plane of view and $<100>\mathrm{c}$-axis out of the plane of the view

\begin{tabular}{|l|l|l|}
\hline $\begin{array}{l}\text { Observed set } \\
\text { of directions }\end{array}$ & $\begin{array}{l}\text { Possible set of } \\
\text { low-index planes }\end{array}$ \\
\hline C-axis in-plane & view \\
\hline$<100>$ & $\{001\}$ & $\{110\}$ \\
\hline$<011\rangle$ & $\{011\}$ & $\{111\}$ \\
\hline$<001\rangle$ & $\{100\}$ & $\{011\}$ \\
\hline C-axis out-of-plane view \\
\hline$<100>$ & $\{100\}$ & $\{011\}$ \\
\hline
\end{tabular}

